\title{
A Comparative Analysis: Various Storage Rules in Container Yards and Their Performances
}

\author{
Yaowen Ma, Kap Hwan Kim* \\ Department of Industrial Engineering, Pusan National University, Busan, Korea
}

(Received: April 16, 2012 / Revised: June 30, 2012 / Accepted: July 31, 2012)

\begin{abstract}
Determining storage locations of containers is an important issue for efficient operation of container terminals. This study assumes a storage yard with a horizontal layout in which blocks are laid out in parallel to the quay and trucks enter at the side of a block to deliver (receive) a container to (from) the yard crane. Various storage rules for determining storage locations of containers are introduced. Simulation studies are conducted for evaluating various rules. The following guidelines are derived from the result of our simulation study: when designing a block, consider a block configuration in which the longest gantry and the longest trolley travel times of rail-mounted gantry cranes (RMGCs) are similar; do not restrict the types of containers that can be stored in a storage area; if different roles are to be assigned to different storage areas, one possible way is to divide a bay into two areas so that some rows in the bay are allocated to inbound containers while the other rows in the same bay are allocated to outbound containers; reserve the space in bay unit for a high productivity of RMGCs but reserve the space in stack unit when the storage space is not enough; when the storage space is not sufficient, allocate storage location in a way of starting from the end and ending at the middle of a block; for reducing the travel distance of internal trucks, provide a higher priority to a block nearer to the berthing position of the corresponding vessel.
\end{abstract}

Keywords: Container Terminals, Storage Location, Simulation

* Corresponding Author, E-mail: kapkim@pusan.ac.kr

\section{INTRODUCTION}

Container terminal is a complicated logistical system that performs various interrelated handling activities for container transfers among vessels and hinterland transportation modes such as trucking and rail. The four basic operations in a container terminal include: discharging inbound containers from vessels; loading outbound containers onto vessels; receiving outbound containers from road trucks or trains; and delivering inbound containers to road trucks or trains for hinterland transportation. Figure 1 shows a yard configuration and container flows in a container terminal. The storage yard consists of blocks. Each block consists of 30-40 bays, each of which consists of 6-0 stacks (rows).

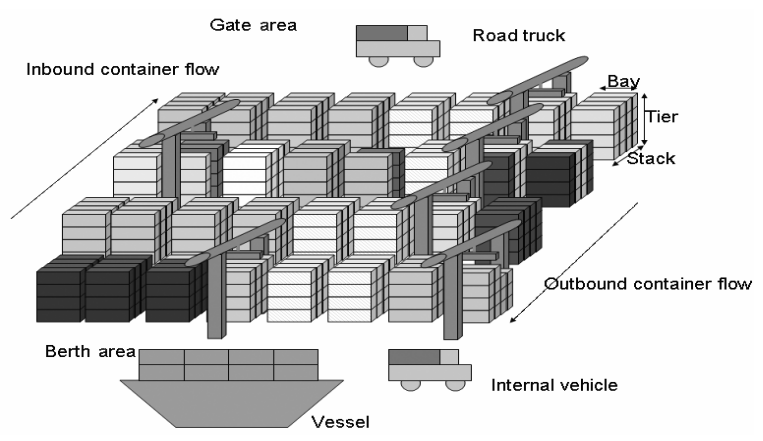

Figure 1. Container flows in container terminals.

The storage rules for inbound containers are relatively simpler than those for outbound containers be- 


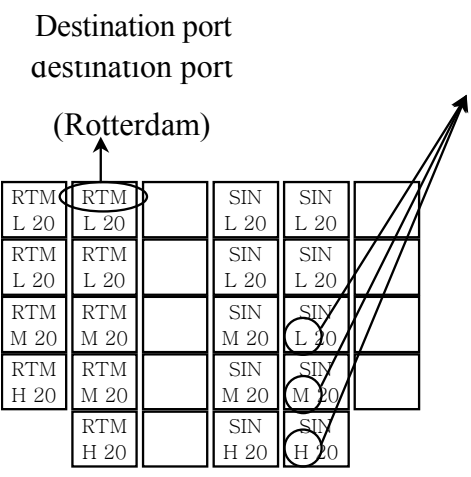

Bay 05
Weight group

we1ght group

(heavy, medium, light)

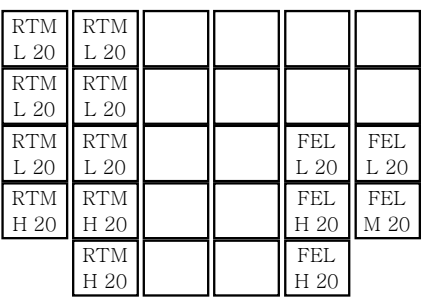

Bay 06

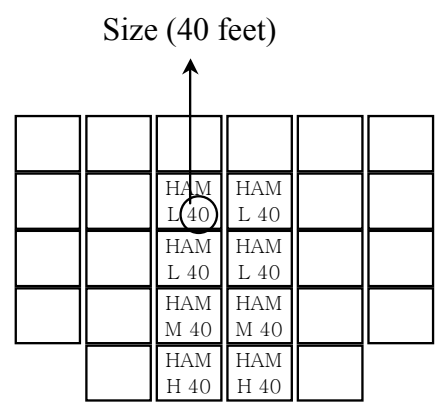

Bay 07

Figure 2. An example of storage plan of a container-ship (Park, 2003).

cause there are fewer constraints to satisfy for inbound containers than for outbound containers. Outbound containers are loaded onto a vessel, and the storage locations of a specific type of outbound containers are constrained by a stowage plan as illustrated in Figure 2 (Park, 2003). The plan shows cells for three bays, for each of which the type (group) of outbound containers to be loaded is specified. The type (group) of containers is defined by the destination port and the size.

For efficient loading operation, several principles are widely accepted with regard to space planning. First, yard-bays that are assigned to a container-ship should be located near the berthing position of the corresponding ship (nearest location principle). Second, containers must be placed at locations that can avoid congestion of the yard cranes and internal trucks (least congestion principle). Thus, containers bound for the same vessel are usually distributed over several blocks.

Third, containers of the same group must be located close to each other in either the same bay or in adjacent bays (concentrated location principle), which is valid only for the indirect transfer systems utilizing both the yard-side equipment (yard cranes or straddle carriers) and prime movers. During the loading operations of containers, containers of the same group are likely to be loaded onto cells that are located close together, as illustrated in Figure 2; thus, they are usually loaded consecutively. Thus, the travel distances of yard cranes can be reduced by placing the containers of the same group in slots that are close to each other. In practice, all the stacks in a yard-bay or in adjacent yard-bays are usually allocated to the same container group. Towards the allocation, all the stacks in a compact area are usually reserved in advance for a specific container group. However, when the size of the reservation is very large, there may be a waste of space, which, in turn, may result in a space shortage for other container groups.

Fourthly, containers must be located in a way that relocations of containers are minimized (least relocation principle). Thus, containers of different groups must not be mixed in the same stack. When containers of different groups are mixed in the same stack, relocations may occur for picking up a container of a group, which is located under the containers of other groups.

Finally, containers must be located so that broken spaces are minimized (minimum broken spaces principle). The amount of broken spaces is measured by summing up the number of empty but reserved slots multiplied by the duration for which the slots remain empty.

Note that the outbound containers include transshipment containers that are discharged from a vessel and loaded onto another vessel. For inbound containers, the first and second principles are popularly used in practice. There may be three hierarchies in decision-making with regard to the storage locations of containers: block selection, bay selection, and stack selection.

Some early studies (Castilho and Daganzo, 1993; Taleb-Ibrahimi et al., 1993; Kim, 1997; Chen, 1999) may be useful for understanding the characteristics of the storage location problem. Practical issues related to storage space allocation are introduced and basic properties related to container handling in storage yards are analyzed. Several studies have examined space planning for container yards. Cao and Uebe (1995) addressed the static and single-period space planning problem in allocating spaces to arriving containers and proposed a transportation-problem formulation to solve the problem. Kim and Park (2003a) and Lim and Xu (2006) addre-ssed the space-allocation problem for export containers that dynamically arrive at the terminal. Kim and Park (2003b) generalized the model of Kim and Park (2003a) so that the model can be used not only for container yards but also for general warehouses. Zhang et al. (2003) generalized the multi-period problem of Kim and Park (2003b) by including, in the objective function, the terms that represent the balancing of handling activities across different storage areas as well as the minimization of the total distance traveled by yard trucks between storage areas and quay cranes. Kim and Kim (1999) addressed the space-allocation problem for import containers in which the stacking height and the amount of space (not the storage locations) are simultaneously determined to dynamically accommodate changing space requirements. The authors proposed a nonlinear programming model 
and a solution method based on Lagrangian relaxation. Cordeau et al. (2007) also addre-ssed the problem of space allocation in services that pertain to incoming or outgoing containers. They attempted to minimize the handling operations that result from the movement from one area of the yard to another when the areas of the incoming and outgoing services differ. Lee et al. (2006) and Han et al. (2008) addressed the yard storage allocation problem by considering traffic congestion as one of the important objectives. They proposed a heuristic procedure for space allocation.

Kim and Bae (1998), Hirashima et al. (2006), Lee and Hsu (2007), and Lee and Chao (2009) addressed how to schedule the re-marshalling operations for outbound containers. Kim et al. (2000) addressed the problem of locating individual outbound containers that incorporate the container weights. Preston and Kozan (2001), Kozan and Preston (2006), and Mattfeld and Kopfer (2003) proposed mathematical models and solution methods for simultaneously determining storage locations and schedules of transfer operations. Dekker et al. (2007) and Saanen and Dekker (2006a, 2006b) introduced various storage determination rules and presented simulation results on the proposed storage rules.

Most of the previous studies proposed mathematical models for allocating storage spaces. Dekker et al. (2007) and Saanen and Dekker (2006a, 2006b) tested storage rules for the yard with blocks perpendicular to the quay. This paper evaluates the effect of different yard configurations and storage strategies on the yard that has blocks parallel to the quay. Section 2 introduces performance measures and storage strategies, Section 3 provides the results of the simulation study, and Section 4 presents the conclusions.

\section{PERFORMANCE MEASURES, DESIGN PARAMETERS, AND RULES FOR CON- TAINER STORAGES}

The productivity of quay cranes $(\mathrm{QCs})$ is one of the most popular performance measures for evaluating container terminals. However, the productivity of QCs is influenced not only by the storage rules but also by many other factors. In addition, the storage rules indirectly affect the productivity of QCs through the efficiency of ship operations. Therefore, the system time of trucks in blocks, the shortage of space in the yard, and the travel time of trucks between QCs and the yard are selected as the performance measures for evaluating the storage rules.

The performance measures are defined as follows. The system time of internal trucks and road trucks implies the total time that these trucks spend at a block beginning from arrival at the block through departure from the same block. It measures the degree of congestion of internal trucks and road trucks at the block and is a function of the service time of yard cranes at the block and the arrival rate of internal trucks and road trucks at the block. The space shortage is another important performance measure of container yards. When arriving containers are not assigned storage space, they have to be moved to an outside yard, which incurs additional costs. The storage locations of containers affect the travel times of trucks. When the QC that discharges or loads a container is far from the storage location of the container in the yard, the internal truck must travel a long distance to deliver the container, which results in a requirement for more internal trucks during the ship operation.

Table 1. Configurations and rules to be compared

\begin{tabular}{|c|c|c|}
\hline Classifications & Abbreviation & Rules or configurations \\
\hline Configuration of blocks & CONFIG & Layout of blocks and specification of each block \\
\hline $\begin{array}{l}\text { Designation of storage areas to a } \\
\text { specific type of containers }\end{array}$ & DESIG & $\begin{array}{l}\text { Role separation of blocks (RSBLOCK) } \\
\text { Role separation of rows (RSROW) } \\
\text { Role separation of bays (RSBAY) } \\
\text { No restriction (NR) }\end{array}$ \\
\hline Reservation unit & UNIT & $\begin{array}{l}\text { Stack (STACK-UNIT) } \\
\text { Bay (BAY-UNIT). }\end{array}$ \\
\hline $\begin{array}{l}\text { Different priorities on blocks for } \\
\text { different berths }\end{array}$ & PRIOBERTH & $\begin{array}{l}\text { Different priorities are given to blocks (PRIORITY-EXIST) } \\
\text { No priority is given (NO-PRIORITY) }\end{array}$ \\
\hline $\begin{array}{l}\text { Number of locations for reserved } \\
\text { spaces }\end{array}$ & NUMRESERVE & $\begin{array}{l}\text { Filling up empty and reserved slots first (MIN-NUMRESERVE) } \\
\text { Multiple reservations allowed (MAX-NUMRESERVE) }\end{array}$ \\
\hline $\begin{array}{l}\text { Sequencing bays or stacks to } \\
\text { reserve }\end{array}$ & SEQUENCE & $\begin{array}{l}\text { Random empty bay (stack) (RANDOM-SEQUENCE) } \\
\text { Endmost empty bay (stack) (ENDMOST-SEQUENCE) }\end{array}$ \\
\hline $\begin{array}{l}\text { Maximum number of internal } \\
\text { trucks and road trucks in a block }\end{array}$ & MAXVEH & The maximum number vehicles to be deployed to a block \\
\hline
\end{tabular}


tion of a block, a bay, or a stack. Here we introduce various storage policies or rules that affect the performance of terminals at strategic, tactical, and operational levels. Table 1 summarizes the rules and configurations to be tested in this paper.

\subsection{Strategic Design Parameters-Configuration of Blocks (CONFIG)}

Many design parameters of the storage area influence the performance of the transfer operation of the yard crane including: 1) the layout of blocks in the yard; 2) the positions of the transfer points of containers between yard cranes and trucks; and 3) the configuration of each block (the number of bays, the number of rows, and the number of tiers). This paper will address the configuration (CONFIG) of blocks and analyze the effect of different configurations on the performance of the yard operation.

\subsection{Designation of Storage Areas to a Specific Type of Containers (DESIG)}

For convenience in the inventory control of containers, many container terminal operators pre-allocate some areas in the yard to a specific type of containers. For example, the areas for inbound containers are designated separately from those for outbound containers. Various designations of areas in the yard to specific types of containers are being used including the following.

- Role Separation of Blocks (RSBLOCK): Each block is assigned to either inbound containers or outbound containers.

- Role Separation of Rows (RSROW): Each block is divided into two parts. One half of the rows in one side of each bay are assigned to outbound containers, while the other half of the rows at the other side are assigned to inbound containers. This policy is usually used for blocks with a large number of rows in a bay and allows the dual-cycle operation of a yard crane in a bay.

- Role Separation of Bays (RSBAY): The storage area for each block is partitioned into two sub-areas. Half the bays of each block, which are near the entrance of the block aisle, will be assigned to inbound containers, while the other half will be assigned to outbound containers. In this way, more dual-cycle operations of internal trucks are expected during the ship operation.

- No Restriction (NR): There is no restriction on the usage of space. Inbound and outbound containers can be located at any place in the yard.

\subsection{Reservation Unit (UNIT)}

According to the concentration principle for the storage locations of outbound containers, some area of the storage space is reserved in advance for a specific group of containers. The two most popular reservation units adopted in practice are 'stack unit' (STACK-UNIT) and 'bay unit' (BAY-UNIT). When the stack unit is used, all the slots in a stack are reserved for containers of the same group. When bay units are used for reservation, all the slots in the same bay are reserved for containers of the same group.

\subsection{Different Priorities on Blocks for Different Berths (PRIOBERTH)}

This is a block selection rule. When the size of a container terminal is large, some blocks are more favored than others by vessels at a specific berth because of the differing travel distances of trucks from the berth to the positions of containers. Thus, when spaces are available at those blocks, the blocks with a higher priority may be considered first as candidate positions for containers than other blocks (PRIORITY-EXIST). Alternatively, no priority may be given for any block (NOPRIORITY).

\subsection{Number of Locations for Reserved Spaces (NUMRESERVE)}

NUMRESERVE is related to a block-selection rule. When the storage space for a container group is reserved in the stack unit or the bay unit for a high utilization of space, empty spaces at the reserved stack or bay must be filled first by arriving containers before a new empty stack or bay is reserved for the same container group (Filling up empty and reserved slots first: MIN-NUMRESERVE). However, in this case, all trucks with containers of the same group will be routed to the same block with the reserved stack or bay, which may result in a congestion of trucks. Thus, each block may be allowed to have a reserved stack (or bay) for a container group (Multiple reservations allowed: MAX-NUMRESERVE). In MAX-NUMRESERVE, after a block is first selected by a block-selection rule, if a stack or a bay exists with empty slots that are reserved for the same container group, the stack or bay will be selected for stacking the arrived container; otherwise, an empty stack or bay will be reserved for the container group.

\subsection{Sequencing Bays or Stacks to Reserve (SEQUENCE)}

The SEQUENCE rule may be a bay-selection rule when the reservation unit is a bay (or a stack-selection rule when the reservation unit is a stack). When a new empty bay or stack is reserved in a block for arriving containers, two types of priority rules can be used: a random bay (stack) (RANDOM-SEQUENCE) or the endmost bay (stack) (ENDMOST-SEQUENCE) among the empty bays (stacks). The endmost-bay (stack) rule selects the empty bay (stack) that is nearest to either end 
of the block, while the random-bay (stack) rule selects a random empty bay (stack) from candidates.

\subsection{Maximum Number of Internal Trucks and Road Trucks in a Block (MAXVEH)}

The MAXVEH storage rule is related to block selection. When the storage location is determined for newly arriving containers, those blocks are excluded from consideration for which the total number of trucks that either wait at the block or head to the block is larger than a specified number. The purpose of this rule is to avoid congestion and long waiting queues at the block.

\section{SIMULATION EXPERIMENTS}

\subsection{Performance Measures and Storage Rules}

The simulation study evaluated various storage rules by using performance measures, such as the average system time of internal vehicles and road trucks during different types of operation, the average shortage in the storage space, and the average travel distance of internal vehicles. Since there are too many combinations of different storage policies or rules, some basic strategies or rules are selected. Unless explicitly mentioned, these basic strategies/rules were assumed in the experiments:

1) DESIG: There is no dedicated area for either inbound or outbound containers in the container yard (No Restriction).

2) PRIOBERTH: A container can be stored in any block in the yard without consideration of the block priority (NO-PRIORITY).

3) UNIT: A stack is reserved for containers of the same group (STACK-UNIT).

4) NUMRESERVE: A new empty stack is reserved for a container group after the previous stack for the same container group becomes completely full (MIN-NUMRESERVE).

5) MAXVEH: The number of vehicles in each block is not considered as a condition for selecting candidate blocks.

6) SEQUENCE: The stack is selected randomly in a block (RANDOM-SEQUENCE).

\subsection{Terminal Configuration and Input Data Used in the Simulation Model}

The simulation models in this section are developed in light of the following handling system and operation scenario. The basic models are constructed by considering a terminal with three berths, wherein blocks are laid out in parallel to the quay. Table 2 details the specifications of each layout. There are two groups of yard layout: those with 24 blocks and those with 12 blocks. Figure 3 shows the layout of the former $(4 \times 6)$. Note that the size of yards with 24 blocks was assumed to be $(295 \times 930 \mathrm{~m})$, while it was $(211 \times 930 \mathrm{~m})$ for yards with 12 blocks. In the consideration of alternative layouts, the aim was to develop layouts that are as similar as possible with regard to the total storage capacity with the proviso that the storage capacity of layouts with 12 blocks was three-fourths of that of the layouts with 24 blocks. The $(4 \times 6)$ and $(4 \times 3)$ layouts are used as the basic models for yards with 24 and 12 blocks, respectively. This means that, if not mentioned explicitly, either of the two layouts will be assumed in the simulation. Each berth has three QCs installed. Each block has two railmounted gantry cranes (RMGCs) of the cantilever type with transfer points at both sides of the bays. The empty and loaded gantry speeds and the empty and loaded hoist speeds of RMGCs were set to $120,30,80$, and $40 \mathrm{~m}$ per minute, respectively, and the trolley speed of RMGCs was set to $120 \mathrm{~m} / \mathrm{min}$. The time required for an RMGC to release or pick-up a container was assumed to be 10 seconds. It was also assumed that the gantry and trolley movements of RMGCs can occur simultaneously. The upper aisle of each block is assigned for road trucks while the lower aisle of each block is assigned for internal vehicles for which the speed was set to $150 \mathrm{~m} / \mathrm{min}$. Five internal trucks were dedicated to each QC.

With regard to input data, data that were collected from Pusan East Container Terminal are used. Raw data, collected from Pusan East Container Terminal, on arrival times of vessels and the number of containers of each vessel were used for the simulation. The arrival times of trucks were analyzed and an empirical distribution of arrival times of trucks was constructed, which was used for generating truck arrival events. In the simulation model, vessels arrive at the terminal for 46 days. The number of vessels that arrive during the period is 74 . The average, maximum, and minimum numbers of load-

Table 2. Different layouts used in the simulation

\begin{tabular}{|lcccccccc|}
\hline Layout & $3 \times 8$ & $4 \times 6$ & $6 \times 4$ & $8 \times 3$ & $2 \times 6$ & $3 \times 4$ & $4 \times 3$ & $6 \times 2$ \\
\hline \hline Number of bays in each block & 14 & 20 & 31 & 43 & 20 & 31 & 43 & 67 \\
Number of stacks in each bay & 29 & 20 & 11 & 6 & 35 & 21 & 14 & 7 \\
Number of tiers & 4 & 4 & 5 & 6 & 4 & 4 & 4 & 5 \\
Number of slots (TEUs) in the yard & 38,976 & 38,400 & 40,920 & 37,152 & 33,600 & 31,248 & 28,896 & 28,140 \\
\hline
\end{tabular}

$\mathrm{A} \times \mathrm{B}$ : "A" and "B" indicate the number of rows and columns of blocks in the yard, respectively. 


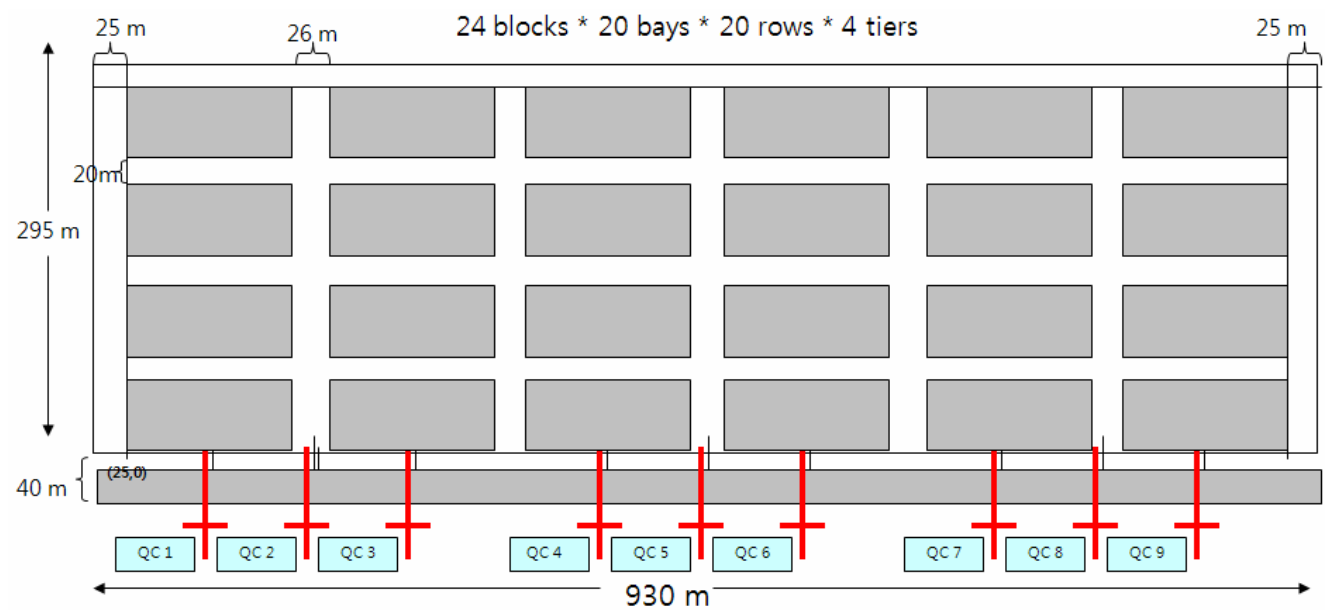

Figure 3. Layout of $(4 \times 6 ; 4$ rows and 6 columns of blocks).

ing containers per vessel are 435, 1,379, and 12, while those of the containers that are discharged are 512, 1,737 , and 10, respectively. The arrivals of road trucks for containers of each vessel are generated by using the distribution of truck arrivals, which spans the timeinterval that begins seven days prior to the arrival of the vessel and continues until seven days after the departure of the vessel.

Statistics were collected for 30 vessels that arrived between the 17 th day and the 28 th day to remove datapoints during the initial and final transient periods. Thus, this is a steady state simulation study. The eM-plant software (Tecnomatix, Plano, TX, USA) was used for the development of the simulation program. For each statistic in the simulation results, the average of the results from five simulation runs was obtained and listed in tables. Statistical tests have been conducted to compare the performances of the system with different rules or configurations. Statements in the following texts are based on the statistical tests. Because of the limitation in the number of pages, however, the test results were omitted. In some cases, simulation runs were conducted in a larger number than 5 for the statistical test purposes.

\subsection{Comparison of the Performance across Different Layouts (CONFIG)}

It is expected that the length and the width of a block affect the cycle time of RMGCs significantly, because they determine the gantry and the trolley travel times of RMGCs. Also, the numbers of vertical and horizontal aisles affect the travel time of trucks. This subsection tests the impacts of these design parameters on the performance of the yard. Table 3 shows the longest travel time of RMGCs in the gantry and trolley directions. Since the two RMGCs are deployed in a block, one half of the block length was considered to be the longest length in the gantry direction. The value of the shape factor of each yard layout configuration, which is the longest trolley travel time divided by the longest gantry travel time, is provided in Table 3 .

Table 3. Longest gantry and trolley travel time of RMGC in a block

\begin{tabular}{|cccc|}
\hline CONFIG & $\begin{array}{c}\text { Gantry travel } \\
\text { time }(\mathrm{a})^{*}\end{array}$ & $\begin{array}{c}\text { Trolley travel } \\
\text { time }(\mathrm{b})^{*}\end{array}$ & $\begin{array}{c}\text { Shape factor } \\
(\mathrm{b}) /(\mathrm{a})\end{array}$ \\
\hline \hline $3 \times 8$ & 17.80 & 29.00 & 1.63 \\
$4 \times 6$ & 25.44 & 20.00 & 0.79 \\
$6 \times 4$ & 39.44 & 11.00 & 0.28 \\
$8 \times 3$ & 54.70 & 6.00 & 0.11 \\
$2 \times 6$ & 25.40 & 35.00 & 1.38 \\
$3 \times 4$ & 39.44 & 21.00 & 0.53 \\
$4 \times 3$ & 54.70 & 14.00 & 0.26 \\
$6 \times 2$ & 85.22 & 7.00 & 0.08 \\
\hline
\end{tabular}

* Values are presented as number (sec).

RMGC: rail-mounted gantry crane.

Tables 4 and 5 list the average system time of road trucks and internal trucks and the average travel distance of internal trucks for different block configurations. Among the layouts with 24 blocks, the average system time of road trucks and internal trucks is the shortest in the $(4 \times 6)$ layout; the next shortest is in the $(3 \times 8)$ layout. Note that in the $(4 \times 6)$ layout, the difference between the longest trolley and gantry movement times is the smallest. The difference is the second smallest in the $(3 \times 8)$ layout. However, in the case of loading and unloading operations that require less frequent gantry travels, the $(6 \times 4)$ layout, which has 11 stacks in a bay, outperformed the $(3 \times 8)$ layout, which has 29 stacks in a bay. Also, note that the average system time during the receiving operation is the shortest, and the corresponding figure during the delivery operation is the longest because of the re-handling that is required for picking up an inbound container. The average travel distance of internal trucks is the shortest in the $(3 \times 8)$ layout in which the number of bays in a block (the length of a block) is the shortest. The results of the layouts with 12 blocks are 
Table 4. Average system time and travel distance for different CONFIG parameters in layouts with 24 blocks

\begin{tabular}{|c|c|c|c|c|c|c|c|}
\hline \multirow{2}{*}{ CONFIG } & \multicolumn{6}{|c|}{ Average system time of trucks (min:sec) } & \multirow{2}{*}{$\begin{array}{l}\text { Travel distance } \\
\text { of internal trucks }\end{array}$} \\
\hline & Road trucks & Internal trucks & Receiving & Loading & Delivery & Unloading & \\
\hline $3 \times 8$ & $3: 19$ & $3: 23$ & 2:09 & $3: 29$ & $4: 13$ & $3: 17$ & 445 \\
\hline $4 \times 6$ & $3: 16$ & 3:07 & 2:07 & $3: 18$ & $4: 18$ & $2: 57$ & 461 \\
\hline $6 \times 4$ & $3: 39$ & $3: 18$ & $2: 16$ & $3: 22$ & $4: 42$ & $3: 15$ & 477 \\
\hline $8 \times 3$ & 4:08 & 3:39 & $2: 30$ & $3: 32$ & $5: 23$ & $3: 44$ & 497 \\
\hline
\end{tabular}

Table 5. Average system time and travel distance for different CONFIG parameters in layouts with 12 blocks

\begin{tabular}{|cccccccc|}
\hline \multirow{2}{*}{ CONFIG } & \multicolumn{5}{c}{ Average system time of trucks (min:sec) } & \multicolumn{2}{c|}{$\begin{array}{c}\text { Travel distance } \\
\text { of internal trucks }\end{array}$} \\
\cline { 2 - 6 } & Road trucks & Internal trucks & Receiving & Loading & Delivery & Unloading & 436 \\
\hline $2 \times 6$ & $3: 18$ & $3: 17$ & $2: 19$ & $3: 06$ & $4: 03$ & $3: 28$ & 434 \\
$3 \times 4$ & $3: 38$ & $3: 37$ & $2: 29$ & $3: 47$ & $4: 30$ & $3: 29$ & 453 \\
$4 \times 3$ & $3: 43$ & $3: 34$ & $2: 36$ & $3: 48$ & $4: 35$ & $3: 22$ & 485 \\
$6 \times 2$ & $4: 35$ & $4: 23$ & $3: 12$ & $4: 22$ & $5: 39$ & $4: 24$ & 4 \\
\hline
\end{tabular}

similar to those with 24 blocks.

\subsection{Comparison of the Performance of the DESIG Storage Rules}

In some terminals, the types of containers that can be stored at a specific area may be restricted for the convenience of the management of containers. It is expected that this restriction will affect the productivity of the yard handling system significantly. Also, a tighter restriction may result in a higher possibility of the storage space shortage. Tables 6 and 7 show that the rule of RSBLOCK, in which a block can receive only outbound or inbound containers, yields the longest average system time of both road and internal trucks. The average sys- tem time of internal trucks was shorter in the cases of RSROW and NR than in the cases of RSBLOCK and RSBAY. The differences are caused by RSROW and NR which tend to distribute the traffic of trucks over a wider area than RSBLOCK or RSBAY. The differences become more apparent in the layouts with 12 blocks than in the layouts with 24 blocks because, in the latter case, the total handling capacity (the number of yard cranes) is smaller than in the former case.

Since the total storage capacity in the layouts with 12 blocks is smaller than that in the layouts with 24 blocks by a quarter of the total capacity, some containers that are unloaded or received cannot find storage locations in the $(4 \times 3)$ and $(6 \times 2)$ layouts. Note that the total storage capacities in the $(4 \times 3)$ and $(6 \times 2)$ layouts

Table 6. Average system time and travel distance for different DESIG parameters of CONFIG with 24 blocks

\begin{tabular}{|cccccc|}
\hline CONFIG & DESIG & $\begin{array}{c}\text { Average system time } \\
\text { of road trucks }\end{array}$ & $\begin{array}{c}\text { Average system time } \\
\text { of internal trucks }\end{array}$ & $\begin{array}{c}\text { Unloading percentage } \\
\text { without space }\end{array}$ & $\begin{array}{c}\text { Receiving percentage } \\
\text { without space }\end{array}$ \\
\hline \hline $3 \times 8$ & RSBLOCK & $3: 24$ & $3: 32$ & 0 & 0 \\
& RSROW & $3: 25$ & $3: 21$ & 0 & 0 \\
& RSBAY & $3: 22$ & $3: 26$ & 0 & 0 \\
$4 \times 6$ & NR & $3: 19$ & $3: 23$ & 0 & 0 \\
& RSBLOCK & $3: 18$ & $3: 12$ & 0 & 0 \\
& RSROW & $3: 17$ & $3: 06$ & 0 & 0 \\
& RSBAY & $3: 17$ & $3: 11$ & 0 & 0 \\
$6 \times 4$ & NR & $3: 16$ & $3: 07$ & 0 & 0 \\
& RSBLOCK & $3: 41$ & $3: 23$ & 0 & 0 \\
& RSROW & $3: 41$ & $3: 18$ & 0 & 0 \\
& RSBAY & $3: 38$ & $3: 20$ & 0 & 0 \\
& NR & $3: 39$ & $3: 18$ & 0 & 0 \\
& RSBLOCK & $4: 12$ & $3: 48$ & 0 & 0 \\
& RSROW & $4: 08$ & $3: 39$ & 0 & 0 \\
\end{tabular}


Table 7. Average system time and travel distance for different DESIG parameters of CONFIG with 12 blocks

\begin{tabular}{|cccccc|}
\hline CONFIG & DESIG & $\begin{array}{c}\text { Average system time } \\
\text { of road trucks }\end{array}$ & $\begin{array}{c}\text { Average system time } \\
\text { of internal trucks }\end{array}$ & $\begin{array}{c}\text { Unloading percentage } \\
\text { without space }\end{array}$ & $\begin{array}{c}\text { Receiving percentage } \\
\text { without space }\end{array}$ \\
\hline \hline $2 \times 6$ & RSBLOCK & $3: 28$ & $3: 40$ & 0 & 0 \\
& RSROW & $3: 26$ & $3: 16$ & 0 & 0 \\
& RSBAY & $3: 22$ & $3: 26$ & 0 & 0 \\
& NR & $3: 18$ & $3: 17$ & 0 & 0 \\
$3 \times 4$ & RSBLOCK & $3: 43$ & $4: 03$ & 0 & 0 \\
& RSROW & $3: 41$ & $3: 34$ & 0 & 0 \\
& RSBAY & $3: 39$ & $3: 38$ & 0 & 0 \\
$4 \times 3$ & NR & $3: 38$ & $3: 37$ & 0 & 0 \\
& RSBLOCK & $3: 52$ & $3: 59$ & 0.002 & 0 \\
& RSROW & $3: 47$ & $3: 34$ & 0.001 & 0 \\
& RSBAY & $3: 44$ & $3: 35$ & 0 & 0 \\
$6 \times 2$ & NR & $3: 43$ & $3: 34$ & 0 & 0 \\
& RSBLOCK & $4: 46$ & $5: 06$ & 0.009 & 0 \\
& RSROW & $4: 33$ & $4: 23$ & 0.002 & 0 \\
\hline
\end{tabular}

are smaller than those in the $(3 \times 4)$ and $(2 \times 6)$ layouts. Also, in the $(6 \times 2)$ layout, because the number of tiers is greater than in the other layouts, the amount of broken space must be larger than that in the other layouts. Note that for the case of 12 blocks, RSBLOCK, RSROW, and RSBAY, which consider fewer candidate stacks than NR, exhibit more shortage than NR.

\subsection{Comparison of the Performance of the UNIT Storage Rules}

When an empty bay is reserved for a type of containers (BAY-UNIT), more empty space must be reserved than when an empty stack is reserved (STACK-UNIT). Thus, different units of reservation may give different levels of space requirements, which is the main issue of the following experiment. Tables 8 and 9 provide the simulation results that compare the performance of the two reservation units, BAY-UNIT and STACK-UNIT, under different block configurations. First of all, the BAY-UNIT reservation results in a significant shortage in space for both the containers that are received and the containers that are discharged. However, it was found that BAY-UNIT outperforms STACK-UNIT in terms of the average system time of trucks and vehicles. This can be explained as follows: because BAY-Unit provides a greater reservation area for containers of the same group, fewer gantry movements of RMGCs are expected, which results in shorter operation times per container on the part of RMGCs, hence the shorter system times of trucks at blocks. However, note that the rejection-because of shortage in the storage space-of some containers that are being received may have partially contributed to the shorter system times of trucks in the case of BAYUNIT.

\subsection{Comparison of the Performance of the PRIOBERTH Storage Rules}

Depending on the berthing position of a vessel, different blocks may have different priorities (PRIORITYEXIST) for the assignment of storage locations of con-

Table 8. Average system time and travel distance for different UNIT parameters for CONFIG with 12 blocks

\begin{tabular}{|cccccc|}
\hline CONFIG & UNIT & $\begin{array}{c}\text { Average system time } \\
\text { of road trucks }\end{array}$ & $\begin{array}{c}\text { Average system time } \\
\text { of internal trucks }\end{array}$ & $\begin{array}{c}\text { Unloading percentage } \\
\text { without space }\end{array}$ & $\begin{array}{c}\text { Receiving percentage } \\
\text { without space }\end{array}$ \\
\hline \hline $2 \times 6$ & Stack & $3: 18$ & $3: 17$ & 0 & 0 \\
& Bay & $2: 29$ & $2: 53$ & 0.901 & 0.646 \\
$3 \times 4$ & Stack & $3: 38$ & $3: 37$ & 0 & 0 \\
& Bay & $2: 34$ & $3: 13$ & 0.896 & 0.592 \\
$4 \times 3$ & Stack & $3: 43$ & $3: 34$ & 0 & 0 \\
& Bay & $2: 40$ & $3: 11$ & 0.883 & 0.538 \\
& Stack & $4: 35$ & $4: 23$ & 0 & 0 \\
& Bay & $3: 21$ & $3: 32$ & 0.793 & 0.401 \\
\hline
\end{tabular}


Ma and Kim: Industrial Engineering \& Management Systems

Vol 11, No 3, September 2012, pp.276-287, (C) 2012 KIIE

Table 9. Average system time and travel distance for different UNIT parameters for DESIG with 12 blocks

\begin{tabular}{|cccccc|}
\hline DESIG & UNIT & $\begin{array}{c}\text { Average system time } \\
\text { of road trucks }\end{array}$ & $\begin{array}{c}\text { Average system time } \\
\text { of internal trucks }\end{array}$ & $\begin{array}{c}\text { Unloading percentage } \\
\text { without space }\end{array}$ & $\begin{array}{c}\text { Receiving percentage } \\
\text { without space }\end{array}$ \\
\hline \hline RSBLOCK & Stack & $3: 52$ & $3: 59$ & 0.002 & 0 \\
& Bay & $3: 34$ & $3: 14$ & 0.754 & 0.658 \\
RSROW & Stack & $3: 47$ & $3: 34$ & 0 & 0 \\
& Bay & $3: 27$ & $3: 12$ & 0.639 & 0.535 \\
RSBAY & Stack & $3: 44$ & $3: 35$ & 0 & 0 \\
& Bay & $2: 45$ & $3: 13$ & 0.870 & 0.540 \\
NR & Stack & $3: 43$ & $3: 34$ & 0 & 0 \\
& Bay & $2: 40$ & $3: 11$ & 0.883 & 0.538 \\
\hline
\end{tabular}

tainers bound for the vessel in order to reduce the travel distance of internal trucks during the ship operation. Considering the travel distances between blocks and berths for vessels to arrive at each berth, storage blocks are assigned with one of the three different priorities. For each berth, a set of blocks nearer to the berth is assigned a higher priority in terms of the assignment of storage locations for the containers of the vessel. If no space is available in a block with the highest priority, then a block with the next highest priority will be the candidate block.

The simulation results for the PRIORITY-EXIST and NO-PRIORITY rules, in which no priority is applied for selecting blocks, are provided in Table 10 for different layouts. Overall, the average system time of trucks for the case of PRIORITY-EXIST was longer than for the case of NO-PRIORIY, which results from the higher congestion of trucks under PRIORITY-EXIT than under NO-PRIORITY. The difference was bigger in the case of internal trucks than in the case of road trucks because the arrival rate of internal trucks during the ship operation is much higher than that of road trucks that arrive randomly. However, the average travel distance of internal trucks is reduced by applying the rule of PRIORITY-EXIST.

\subsection{Comparison of the Performance of the NUMRESERVE Storage Rules}

When we have more candidate blocks for the same type of containers, then it is expected that there will be a higher chance to avoid traffic congestion but at the same time a greater storage space requirement. This section compares the performance of MAX-NUMRESERVE and MIN-NUMRESERVE for different rules of DESIG. The results of the simulation study listed in Table 11 do not show much difference between the two rules.

\subsection{Comparison of the Performance of the SEQUENCE Storage Rules}

When 40 foot containers are located in a block, because they require two slots of $20 \mathrm{ft}$, it is expected that more candidate positions can be provided when containers are filled from the ends of the block (ENDMOSTSEQUENCE) rather than when they are filled in a random order (RANDOM-SEQUENCE). In Table 12, RANDOMSEQUENCE and ENDMOST-SEQUENCE are compared with each other jointly with the rules of DESIG in terms of the system time of trucks and the shortage of space. The simulation result showed a small difference in the

Table 10. Average system time and travel distance for different PRIOBERTH parameters for CONFIG with 12 blocks

\begin{tabular}{|ccccccc|}
\hline CONFIG & PRIOBERTH & $\begin{array}{c}\text { Average } \\
\text { system time } \\
\text { of road trucks }\end{array}$ & $\begin{array}{c}\text { Average } \\
\text { system time } \\
\text { of internal trucks }\end{array}$ & $\begin{array}{c}\text { Travel distance } \\
\text { of internal } \\
\text { trucks }\end{array}$ & $\begin{array}{c}\text { Unloading } \\
\text { percentage } \\
\text { without space }\end{array}$ & $\begin{array}{c}\text { Receiving } \\
\text { percentage } \\
\text { without space }\end{array}$ \\
\hline \hline $2 \times 6$ & No prior & $3: 18$ & $3: 17$ & 436 & 0 & 0 \\
& Prior & $3: 23$ & $3: 56$ & 240 & 0 & 0 \\
$4 \times 4$ & No prior & $3: 38$ & $3: 37$ & 434 & 0 & 0 \\
& Prior & $3: 47$ & $4: 16$ & 278 & 0 & 0 \\
& No prior & $3: 43$ & $3: 34$ & 453 & 0 & 0 \\
& Prior & $3: 55$ & $4: 14$ & 300 & 0 & 0 \\
& No prior & $4: 35$ & $4: 23$ & 485 & 0 & 0 \\
& Prior & $5: 10$ & $5: 20$ & 386 & 0 & 0 \\
\hline
\end{tabular}


Table 11. Average system time and travel distance for different NUMRESERVE parameters for DESIG with 12 blocks $(4 \times 3)$

\begin{tabular}{|cccccc|}
\hline DESIG & NUMRESERVE & $\begin{array}{c}\text { Average system } \\
\text { time of road } \\
\text { trucks }\end{array}$ & $\begin{array}{c}\text { Average system } \\
\text { time of internal } \\
\text { trucks }\end{array}$ & $\begin{array}{c}\text { Unloading } \\
\text { percentage } \\
\text { without space }\end{array}$ & $\begin{array}{c}\text { Receiving } \\
\text { percentage } \\
\text { without space }\end{array}$ \\
\hline \hline RSBLOCK & Min num-reserve & $3: 52$ & $3: 59$ & 0.002 & 0 \\
& Max num-reserve & $3: 53$ & $4: 03$ & 0.002 & 0 \\
RSROW & Min num-reserve & $3: 47$ & $3: 34$ & 0.001 & 0 \\
& Max num-reserve & $3: 47$ & $3: 35$ & 0.001 & 0 \\
RSBAY & Min num-reserve & $3: 44$ & $3: 35$ & 0 & 0 \\
& Max num-reserve & $3: 44$ & $3: 35$ & 0.001 & 0 \\
& Min num-reserve & $3: 43$ & $3: 34$ & 0 & 0 \\
\hline
\end{tabular}

Table 12. Average system time and travel distance for different SEQUENCE parameters for DESIG with 12 blocks $(4 \times 3)$

\begin{tabular}{|cccccc|}
\hline DESIG & SEQUENCE & $\begin{array}{c}\text { Average system } \\
\text { time of road } \\
\text { trucks }\end{array}$ & $\begin{array}{c}\text { Average system } \\
\text { time of internal } \\
\text { trucks }\end{array}$ & $\begin{array}{c}\text { Unloading } \\
\text { percentage } \\
\text { without space }\end{array}$ & $\begin{array}{c}\text { Receiving } \\
\text { percentage } \\
\text { without space }\end{array}$ \\
\hline \hline RSBLOCK & Random & $3: 52$ & $3: 59$ & 0.002 & 0 \\
RSROW & Endmost & $3: 49$ & $4: 10$ & 0 & 0 \\
& Random & $3: 47$ & $3: 34$ & 0.001 & 0 \\
RSBAY & Endmost & $3: 45$ & $3: 37$ & 0 & 0 \\
& Random & $3: 44$ & $3: 35$ & 0 & 0 \\
NR & Endmost & $3: 43$ & $3: 41$ & 0 & 0 \\
& Random & $3: 43$ & $3: 34$ & 0 & 0 \\
\hline
\end{tabular}

average system time of road trucks, while ENDMOSTSEQUENCE yielded a longer average system time of internal trucks, which resulted from the increased congestion of yard cranes and internal trucks, greater than RANDOM-SEQUENCE. However, RANDOM-SEQUENCE resulted in a greater possibility of space shortage than the ENDMOST-SELECTION rule, because under RANDOM-SEQUENCE, the probability that two consecutive $20 \mathrm{ft}$ bays, which are required for storing $40 \mathrm{ft}$ containers, remain empty becomes lower than in the case of ENDMOST-SEQUENCE.

\subsection{Comparison of the Performance of the MAXVEH Storage Rules}

Because the traffic congestion of vehicles influences the performance of the yard significantly, the rule for locating containers can restrict the number of vehicles (MAXVEH) that are routed to a block. Table 13 compares the simulation results for different maximum numbers of vehicles that are allowed (MAXVEH) per block in various layouts. When MAXVEH $=3$, the average system time of trucks is less than that in the other cases, although the difference in the average system time is small. However, when MAXVEH $=3$, there is a higher possibility of space shortage than that in the other cases.
Table 14 summarizes the results of the simulation experiments in the form of guidelines for locating containers in the yard.

\section{CONCLUSION}

This paper analyzed storage rules for locating containers in the container yards of 8 different layouts. The 8 layout alternatives were evaluated in terms of the average system time of trucks and space shortage in the yard. The storage rules analyzed included the designation policies on storage areas for specific types of containers (RSBLOCK, RSBAY, RSROW, and NR), priority rules for selecting blocks for each berthing position of vessels (PRIORITY-EXSIT and NO-PRIORITY), and the reservation unit for outbound containers (BAY-UNIT and STACK-UNIT). Either more than one reserved stack (MAX-NUMRESERVE) or only one reserved stack (MIN-NUMRESERVE) may be allowed for a container group. Empty spaces for locating containers may be selected either from the endmost position (ENDMOSTSEQUENCE) or randomly (RANDOM-SEQUENCE).

The following conclusions are drawn from an analysis of the performance through simulation studies on configurations of blocks and storage strategies. The simulation result of block configurations indicates that the 
Table 13. Average system time and travel distance for different MAXVEH parameters for DESIG with 12 blocks $(4 \times 3)$

\begin{tabular}{|cccccc|}
\hline DESIG & MAXVEH & $\begin{array}{c}\text { Average system } \\
\text { time of road } \\
\text { trucks }\end{array}$ & $\begin{array}{c}\text { Average system } \\
\text { time of internal } \\
\text { trucks }\end{array}$ & $\begin{array}{c}\text { Unloading } \\
\text { percentage } \\
\text { without space }\end{array}$ & $\begin{array}{c}\text { Receiving } \\
\text { percentage } \\
\text { without space }\end{array}$ \\
\hline \hline RSBLOCK & 3 & $3: 46$ & $3: 38$ & 0.003 & 0 \\
& 7 & $3: 50$ & $3: 49$ & 0 & 0 \\
RSROW & 12 & $3: 49$ & $3: 53$ & 0.001 & 0 \\
& 18 & $3: 50$ & $4: 00$ & 0 & 0 \\
& 3 & $3: 44$ & $3: 25$ & 0 & 0 \\
RSBAY & 7 & $3: 47$ & $3: 33$ & 0 & 0 \\
& 12 & $3: 46$ & $3: 36$ & 0.002 & 0 \\
& 18 & $3: 47$ & $3: 34$ & 0.001 & 0 \\
NR & 3 & $3: 42$ & $3: 27$ & 0.003 & 0 \\
& 7 & $3: 45$ & $3: 34$ & 0.001 & 0 \\
& 12 & $3: 45$ & $3: 33$ & 0 & 0 \\
& 18 & $3: 44$ & $3: 35$ & 0 & 0 \\
& 3 & $3: 43$ & $3: 27$ & 0 & 0 \\
\hline
\end{tabular}

Table 14. Guidelines for locating containers

\begin{tabular}{|cl|}
\hline No & \multicolumn{1}{c|}{ Guidelines } \\
\hline \hline 1 & $\begin{array}{l}\text { When designing a block, consider a block configuration in which the longest gantry and the longest trolley travel times of } \\
\text { rail-mounted gantry cranes (RMGCs) are similar }\end{array}$ \\
2 & $\begin{array}{l}\text { Do not restrict types of containers that can be stored in a storage area } \\
3\end{array}$ \\
If different roles are to be assigned to different storage areas, then one possible way is to divide a bay into two areas so \\
that some rows in a bay are allocated to inbound containers while the other rows in the same bay to outbound containers \\
4 & $\begin{array}{l}\text { Reserve the space in bay unit for a high productivity of RMGCs but reserve in stack unit when the storage space is not } \\
\text { enough }\end{array}$ \\
5 & $\begin{array}{l}\text { When the storage space is not sufficient, allocate storage location in a way of starting from the end and ending at the mid- } \\
\text { dle of a block }\end{array}$ \\
6 & $\begin{array}{l}\text { For reducing the travel distance of internal trucks, provide the higher priority to the block nearer to the berthing position } \\
\text { of the corresponding vessel }\end{array}$ \\
\hline
\end{tabular}

yard blocks with the smallest difference between the longest gantry and the longest trolley travel times of RMGCs yielded the shortest system time of trucks. RSBLOCK, in which a block can either receive only outbound or inbound containers, yields the longest average system time of both road and internal trucks. The average system time of internal trucks is shorter in the cases of RSROW and NR than in the cases of RSBLOCK and RSBAY. The RSBLOCK, RSROW, and RSBAY, which have fewer candidate stacks than NR, entail a higher possibility of space shortage than NR. The BAYUNIT reservation strategy entails a much higher possibility of space shortage than the STACK-UNIT reservation strategy for both the containers that are being received and the containers that are being discharged. However, it was found that BAY-UNIT outperforms STACKUNIT in terms of the average system time of trucks and vehicles. The average system time of trucks for the case of PRIORITY-EXIST is longer than that for the case of
NO-PRIORIY. The difference is bigger in the case of internal trucks than in the case of road trucks. However, the average travel distance of internal trucks is reduced by applying the rule of PRIORITY-EXIST. The MAXNUMRESERVE and MIN-NUMRESERVE do not show much difference with regard to the average system time of trucks and the average space shortage. Comparison of RANDOM-SEQUENCE and ENDMOST-SEQUENCE revealed a small difference in the average system time of road trucks, while ENDMOST-SEQUENCE yielded a longer average system time of internal trucks. However, RANDOM-SEQUENCE had a higher possibility of space shortage than the ENDMOST-SELECTION rule. When the maximum number of vehicles allowed per block (MAXVEH) becomes small, the average system time of trucks increases. However, the average system time was not so sensitive to MAXVEH. However, when MAXVEH becomes smaller, the possibility of the space shortage becomes larger. 


\section{ACKNOWLEDGMENTS}

This work was supported by the National Research Foundation of Korea Grant (NRF-2012000562).

\section{REFERENCES}

Cao, B. and Uebe, G. (1995), Solving transportation problems with nonlinear side constraints with tabu search, Computers and Operations Research, 22(6), 593-603.

Castilho, B. D. and Daganzo C. F. (1993), Handling strategies for import containers at marine terminals, Transportation Research Part B, 27(2), 151-166.

Chen, T. (1999), Yard operations in the container terminal-a study in the 'unproductive moves', Maritime Policy and Management, 26(1), 27-38.

Cordeau, J. F., Gaudioso, M., Laporte, G., and Moccia, L. (2007), The service allocation problem at the Gioia Tauro Maritime Terminal, European Journal of Operational Research, 176(2), 1167-1184.

Dekker, R., Voogd, P., and van Asperen, E. (2007), Advanced methods for container stacking, OR Spectrum, 28(4), 563-586.

Han, Y., Lee, L. H., Chew, E. P., and Tan, K. C. (2008), A yard storage strategy for minimizing traffic congestion in a marine container transshipment hub, OR Spectrum, 30(4), 697-720.

Hirashima, Y., Takeda, K., Harada, S., Deng, M., and Inoue, A. (2006), A Q-learning for group-based plan of container transfer scheduling, JSME International Journal Series C, 49(2), 473-479.

Kim, K. H. (1997), Evaluation of the number of rehandles in container yards, Computers and Industrial Engineering, 32(4), 701-711.

Kim, K. H., Park, Y. M., and Ryu, K.-R. (2000), Deriving decision rules to locate export containers in container yards, European Journal of Operational Research, 124(1), 89-101.

Kim, K. H. and Bae, J. W. (1998), Re-marshaling export containers in port container terminals, Computers and Industrial Engineering, 34(3/4), 655-658.

Kim, K. H. and Kim, H. B. (1999), Segregating space allocation models for container inventories in port container terminals, International Journal of Production Economics, 59(1-3), 415-423.

Kim, K. H. and Park, K. T. (2003a), A note on a dynamic space-allocation method for outbound containers, European Journal of Operational Research,
148(1), 92-101.

Kim, K. H. and Park, K. T. (2003b), Dynamic space allocation for temporary storage, International Journal of Systems Sciences, 34(1), 11-20.

Kozan, E. and Preston, P. (2006), Mathematical modelling of container transfers and storage locations at seaport terminals, OR Spectrum, 28(4), 519-537.

Lee, L. H., Chew, E. P., Tan, K. C., and Han, Y. (2006), An optimization model for storage yard management in transshipment hubs, OR Spectrum, 28(4), 539-561.

Lee, Y. and Chao, S.-L. (2009), A neighborhood search heuristic for pre-marshalling export containers, European Journal of Operational Research, 196(2), 468-475.

Lee, Y. and Hsu, N.-Y. (2007), An optimization model for the container pre-marshalling problem, Computers and Operations Research, 34(11), 3295-3313.

Lim, A. and Xu, Z. (2006), A critical-shaking neighborhood search for the yard allocation problem, European Journal of Operational Research, 174(2), 12471259.

Mattfeld, D. C. and Kopfer, H. (2003), Terminal operations management in vehicle transshipment, Transportation Research Part A, 37(5), 435-452.

Park K. T. (2003), Optimal space allocation and its applications, PhD Thesis, Pusan National University, Busan, Korea.

Preston, P. and Kozan, E. (2001), An approach to determine storage locations of containers at seaport terminals, Computers and Operations Research, 28 (10), 983-995.

Saanen, Y. A. and Dekker, R. (2006a), Intelligent stacking as way out of congested yards? Part 1, Port Technology International, 31, 87-92.

Saanen, Y. A. and Dekker, R. (2006b), Intelligent stacking as way out of congested yards? Part 2, Port Technology International, 32, 80-86.

Taleb-Ibrahimi, M., de Castilho, B., and Daganzo, C. F. (1993), Storage space vs handling work in container terminals, Transportation Research Part B, 27(1), 13-32.

Zhang, C., Liu, J., Wan, Y.-W., Murty, K. G., and Linn, R. J. (2003), Storage space allocation in container terminals, Transportation Research Part B, 37(10), 883-903. 